\title{
Urban traffic and pollutant exposure related to respiratory outcomes and atopy in a large sample of children
}

\author{
T. Nicolai*, D. Carr*, S.K. Weiland", H. Duhme", O. von Ehrenstein*, C. Wagner*, E. von Mutius*
}

Urban traffic and pollutant exposure related to respiratory outcomes and atopy in a large sample of children. T. Nicolai, D. Carr, S.K. Weiland, H. Duhme, O. von Ehrenstein, C. Wagner, E. von Mutius. (C) ERS Journals Ltd 2003.

ABSTRACT: Conflicting results have been reported for the relationship between traffic exposure and inception of atopy. The effect of traffic on the prevalence of asthma and atopy at school age was investigated in a representative population.

Random samples of schoolchildren $(n=7,509$, response rate $83.7 \%)$ were studied using the International Study of Asthma and Allergies in Childhood phase-II protocol with skin-prick tests, measurements of specific immunoglobulin $E$ and lung function. Traffic exposure was assessed via traffic counts and by an emission model which predicted soot, benzene and nitrogen dioxide $\left(\mathrm{NO}_{2}\right)$.

Traffic counts were associated with current asthma, wheeze and cough. In children with tobacco-smoke exposure, traffic volume was additionally associated with a positive skin-prick test. Cough was associated with soot, benzene and $\mathrm{NO}_{2}$, current asthma with soot and benzene, and current wheeze with benzene and $\mathrm{NO}_{2}$. No pollutant was associated with allergic sensitisation.

High vehicle traffic was associated with asthma, cough and wheeze, and in children additionally exposed to environmental tobacco smoke, with allergic sensitisation. However, effects of socioeconomic factors associated with living close to busy roads cannot be ruled out.

Eur Respir J 2003; 21: 956-963.
*University Children's Hospital, Munich, ${ }^{\#}$ Dept of Epidemiology, University of Ulm Ulm, Institute of Epidemiology and Social Medicine, University of Münster, Münster, Germany.

Correspondence: T. Nicolai

University Children's Hospital

Munich

Germany

Fax: 498951604409

E-mail: tnicolai@kk-i.med.uni-muenchen.de

Keywords: Asthma

atopy

children

pollutants

respiratory

traffic

Received: May 172002

Accepted after revision: January 62003
During the last $50 \mathrm{yrs}$, respiratory allergic diseases have increased in children in many countries with modern living conditions. At the same time, car traffic and air-pollution levels have undergone large changes. At sufficiently high concentrations, pollutants such as particulate matter, sulphur dioxide $\left(\mathrm{SO}_{2}\right)$, car exhaust and ozone are known to be associated with respiratory symptoms. While it is well accepted that air pollution can trigger symptoms in children with established asthma [1], its influence on the inception of asthma and allergies is not known. It would be of major concern if the increasing prevalence was, at least in part, due to traffic-related air pollution.

In cities, car traffic accounts for almost all benzene and most of the nitrogen dioxide $\left(\mathrm{NO}_{2}\right)$ and carbon monoxide, but only for a small fraction of $\mathrm{SO}_{2}$ [2]. Fine dust [2], latex particles and black smoke are other emissions related to motor vehicles. Animal and in vitro human experiments [3-5] point towards an effect of diesel exhaust on allergic sensitisation. Traffic-related pollutants have been suggested to alter the antigenicity of pollen and might thereby cause increased allergic sensitisation or precipitate symptoms in allergic subjects [6-8].

Most, but not all, paediatric epidemiological studies found a consistent but small effect of long-term exposure to car traffic or its emissions on respiratory symptoms and lung function [2, 9-14]. A large cross-sectional study using pollutant exposure measured on a $1-\mathrm{km}^{2}$ grid in Dresden, Germany, found increased cough, bronchitis and nonatopic asthma, but no effect on atopic asthma and allergies [2]. However, due to the German reunification process, pollutant exposure has

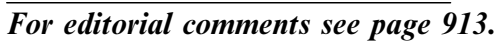

changed greatly during the lifetime of these children. More doctor-diagnosed asthma was reported in children living within $100 \mathrm{~m}$ of a freeway compared with those living farther away [15].

The relationship between allergy and traffic exposure is less consistent. A recent study in Switzerland found increased allergic sensitisation (but no relation to symptoms) in a subgroup of adults living for $>10$ yrs on a busy road [16]. However, a number of paediatric studies found no increase in allergy with measured traffic exposure [2, 9, 12, 13].

The conflicting results of the epidemiological studies are at least partly attributable to small sample sizes in some studies, the difficulty of separating socioeconomic variables from traffic exposure, and reporting bias for self-reported traffic exposure and symptoms. As the reported effect size is mostly rather small, the sample must be sufficiently large to detect or exclude a possible association. Also, exposure assessment is difficult but critical in such studies.

The purpose of this study was to determine the relationship between vehicle-traffic counts and estimated pollutant levels at the place of residence and reported respiratory symptoms, doctor diagnoses and measured allergic sensitisation and respiratory function in a large random sample of children.

\section{Methods}

\section{Study population and study design}

An International Study of Asthma and Allergies in Childhood (ISAAC) phase-II cross-sectional survey was performed 
in Munich, Germany, with $\sim 1.3$ million inhabitants [17]. Random samples of school classes were selected in two age groups: school beginners aged 5-7 yrs and schoolchildren of the fourth grade aged 9-11 yrs. Questionnaires were given to parents, and children underwent skin-prick tests, blood sampling, lung function testing and bronchial challenge if written informed consent had been obtained from the parents. The local ethics committee had approved the study.

\section{Questionnaires}

The questionnaires included the ISAAC core questions on symptoms of asthma, allergic rhinitis and atopic eczema, which have been reported in detail elsewhere [18, 19], and were administered between September 1995-December 1996. Current wheeze was defined as wheezing in the last 12 months. Children were defined as having asthma if their parents reported that asthma had been diagnosed at least once or that a doctor had diagnosed asthmatic, or spastic or obstructive bronchitis more than once. Asthma with symptoms in the last 12 months was defined as current asthma. Hay fever and atopic dermatitis were defined by a reported diagnosis from a doctor. The questionnaire included detailed questions about the child's nationality, the family history of atopic diseases, the number of siblings, and several other potential confounding factors, such as environmental tobacco smoke (ETS) exposure and parental education as a marker of socioeconomic status (SES). SES was defined as highest parental school education; high SES being $>12$ yrs of school education or university. ETS was defined as any current exposure to cigarettes, pipes or cigars in the home.

\section{Skin-prick tests}

All children in the 9-11 yrs age group were invited to participate in skin-prick testing, whereas in the younger age group only a random subsample $(n=1,875)$ was selected. The sensitivity to six common aeroallergens (Dermatophagoides pteronyssinus, D. farinae, tree pollen, grass pollen, Alternaria tenuis and cat dander) was assessed using standardised extracts (ALK, Hørsholm, Denmark) and ALK lancets. A positive (histamine $10 \mathrm{mg} \cdot \mathrm{mL}^{-1}$ ) and negative control were added. The weal size after $15 \mathrm{~min}$ was defined as the mean of the longest diameter and the length of its perpendicular diameter. Children with a weal reaction $\geqslant 3 \mathrm{~mm}$ after subtraction of the reaction to the negative control, to one or more of the allergens tested, were considered to be atopic.

\section{Blood sampling and laboratory analyses}

As with skin-prick testing, all children in the 9-11 yrs age group were asked to provide a blood sample, whereas in the younger age group only a random subsample $(n=1,875$ in Munich) was selected. Serum was separated by centrifugation, frozen and stored at $-70^{\circ} \mathrm{C}$ before analysis. A screening test (SX1 test; Pharmacia, Uppsala, Sweden) was used to detect specific serum immunoglobulin (Ig)E antibodies to a wide array of aeroallergens (D. pteronyssinus, mixed grass pollen, birch pollen, mugwort pollen, cat dander, dog dander and Cladosporium herbarum) in one central laboratory at the University of Berlin. Atopic sensitisation was assumed to be present if a level of $\geqslant 0.7 \mathrm{kU} \cdot \mathrm{L}^{-1}$ of specific serum IgE was measured.

\section{Pulmonary function testing and bronchial challenge}

Because of the long duration of the bronchial challenge protocol, only a random subsample of the children aged 9-11 yrs was invited to participate $(n=2,019)$. Lung function was measured with a spirometer (MasterScope; Jäger, Würzburg, Germany). The criteria for completion of reproducible and satisfactory spirograms as set by the American Thoracic Society [20] were followed. Airway responsiveness was assessed using a $4.5 \%$ hyperosmolar saline challenge [17, 21]. Each subject, whose baseline forced expiratory volume in one second (FEV1) was $>75 \%$ predicted [22], inhaled the saline solution for periods of increasing duration $(0.5,1,2,4$, and $8 \mathrm{~min}$ ). The challenge was stopped after the FEV1 had fallen by $\geqslant 15 \%$ (bronchial hyperresponsiveness positive) or if the total inhalation period of $15.5 \mathrm{~min}$ had been completed.

\section{Traffic exposure assessment}

Average daily traffic counts were performed by the city administration for all streets with an a priori estimated vehicle count of $>4,000 \cdot$ day $^{-1}$. This resulted in counts being available for 1,840 street segments (of a total of 19,000). In addition, measurements of yearly average concentrations of trafficassociated pollutants (benzene, soot and $\mathrm{NO}_{2}$ ) at 18 heavy traffic sites in the city, and from 16 low-to-medium traffic sites were performed [23]. Traffic counts were measured in 1995; air pollution data from December 1996-February 1998.

The street segments with traffic counts and the address of each child were entered into a computer-based geographical information system (GIS). By setting a distance limit of $50 \mathrm{~m}$ around each child's home, the program identified all street segments with traffic counts within this distance, and the sum of their daily traffic counts was used to characterise traffic exposure for this child. This distance limit was used according to published data showing that the effect of car traffic decreases greatly approximately beyond this distance [24].

In a second step, the traffic-count categories of 0-50 $\mathrm{m}$ and $>50-300 \mathrm{~m}$ and other available traffic characteristics (trafficjam percentage) were used to validate a model predicting average yearly pollutant levels as measured at these 34 monitors. The details of this modelling approach are described in another paper [23]. In short, a model using car-traffic counts and a weighting function, to account for the distance between measurement point and street, together with street characteristics (mainly per cent of time with stop-and-go conditions in the segment), was used to derive pollutant estimates. The parameters of this model were optimised to give the best fit for the available actual pollutant-measurement data at the monitoring sites. The monitoring sites had been selected in a way to include both areas of high and low exposure. This model gave a very good estimate of the measured pollutants at low/medium and high exposure locations (benzene $\mathrm{R}^{2}=0.80$, soot $0.80, \mathrm{NO}_{2} 0.77$ ). This model was then used to calculate predicted pollution levels at each child's home address as exposure estimate.

\section{Statistical analyses}

As the expected effect of traffic was rather small, a highexposure group was defined for comparison with less-exposed children. For traffic counts, the children with one or more traffic counts at $\leqslant 50 \mathrm{~m}$ from their home ( $16.3 \%$ of all children) were considered at high exposure. This high-exposure group was then divided into tertiles to assess a possible dose/ response relationship, and was compared with the rest of the 
Table 1.-Participation rates

\begin{tabular}{lccr}
\hline & All Munich children & German children & German children with test $^{\#}$ \\
\hline Parental questionnaire & $6244 / 7509(83.2)$ & $4777 / 6198(77.1)$ & $3953 / 6198(63.8)$ \\
Skin-prick test & $3422 / 5705(60.0)$ & $2577 / 3710(69.5)$ & $2233 / 3710(60.2)$ \\
Serum sample & $2569 / 5705(45.0)$ & $1895 / 3710(51.1)$ & $1656 / 3710(44.6)$ \\
Bronchial challenge & $1140 / 2019(56.5)$ & $904 / 1381(65.5)$ & $771 / 1318(55.8)$ \\
\hline
\end{tabular}

Data are presented as $\mathrm{n} /$ total n (\%). ${ }^{\#}$ : plus geographically referenced address, stored in the geographical information system.

study sample $(83.7 \%)$. The threshold distance was later changed to 100 and $300 \mathrm{~m}$ for sensitivity analyses to assess consistency of results across various cut-offs. The children with no traffic count $\leqslant 300 \mathrm{~m}$ were considered at very low exposure $(22.7 \%$ of all children).

For the pollutant levels, as derived from the validated model, the same proportion of children (i.e. 16.3\%) at the upper end of the exposure distribution as in the $50 \mathrm{~m} \mathrm{limit}$ analysis of the traffic counts was regarded as highly exposed, and this group was again divided into tertiles for the assessment of dose/response effects.

Multiple logistic regression analyses including known relevant confounding variables (age, sex, ETS exposure, SES, family history of asthma, hay fever or eczema) were used to calculate odds ratios for the influence of traffic exposure on the outcome variables. The rationale to stratify for ETS came from another paper published recently by the present group [25], which showed a strong interaction between ETS and low $\alpha_{1}$-antitrypsin serum levels resulting in low lung function among children with both exposures. The authors therefore reasoned that ETS might make the airways more susceptible to other potentially damaging factors, such as pollutant exposure.

\section{Results}

The questionnaire was distributed to 7,509 children in Munich (table 1). The proportion of children without German nationality was $23.1 \%(\mathrm{n}=1,431)$ in Munich. As reported elsewhere, reporting behaviour and socioeconomic variables were profoundly different with regard to ethnic background [26]. Therefore, the analysis presented here was restricted to children with German nationality. Of the eligible German children for whom the questionnaire was returned, skin-prick tests were obtained in 2,577 $(69.5 \%$, table 1). Table 2 shows the prevalence of health outcomes for all German children.

Table 2.-Prevalences of health outcomes

\begin{tabular}{ll}
\hline Current asthma\# & \\
Current wheeze $^{\#}$ & $203 / 3946(5.1)$ \\
Morning cough $^{\#}$ & $342 / 3889(8.8)$ \\
Hay fever & $734 / 3908(18.8)$ \\
Any skin-test reactivity $\geqslant 3 \mathrm{~mm}$ & $453 / 3892(11.6)$ \\
Skin-test reactivity pollen $\geqslant 3 \mathrm{~mm}$ & $436 / 2233(19.5)$ \\
Skin-test reactivity against indoor & $317 / 2224(14.3)$ \\
$\quad$ allergens $\geqslant 3 \mathrm{~mm}$ & $256 / 2233(11.5)$ \\
$\quad \begin{array}{l}\text { Specific IgE against aeroallergens } \\
\quad \geqslant 0.7 \mathrm{kU} \cdot \mathrm{mL}^{-1}\end{array}$ & $592 / 1656(35.8)$ \\
$\quad \begin{array}{l}\text { Specific IgE against food allergens } \\
\quad \geqslant 0.7 \mathrm{kU} \cdot \mathrm{mL}^{-1}\end{array}$ & $181 / 679(26.7)$ \\
Bronchial hyperreactivity & \\
\end{tabular}

Data are presented as $\mathrm{n} /$ total $\mathrm{n}(\%)$. Ig: immunoglobulin. \#: with respective symptoms during the last 12 months.
Table 3.-Outcomes and exposures in children participating and nonparticipating in skin-prick testing (SPT)

\begin{tabular}{lcc}
\hline & With SPT & Without SPT \\
\hline Current asthma\# $^{\#}$ & $4.4(3.7-5.4)$ & $6.1(5.0-7.3)$ \\
Current wheeze $^{\#}$ & $8.2(7.1-9.4)$ & $9.6(8.3-11.1)$ \\
Morning cough $^{\#}$ & $18.9(17.3-20.6)$ & $18.7(16.9-20.6)$ \\
Hay fever & $13.1(11.8-14.6)$ & $9.7(8.4-11.2)$ \\
No traffic count $<50 \mathrm{~m}$ & $83.4(81.8-84.9)$ & $84.1(82.3-85.8)$ \\
Low traffic counts & $5.3(4.5-6.3)$ & $5.4(4.4-6.6)$ \\
Medium traffic counts & $5.7(4.8-6.7)$ & $5.4(4.4-6.5)$ \\
High traffic counts $^{\S}$ & $5.6(4.7-6.6)$ & $5.2(4.2-6.3)$
\end{tabular}

Data are presented as \% $\left(95 \%\right.$ confidence interval). ${ }^{*}$ : with respective symptoms during last 12 months; $\%$ : 2600-15000 vehicles $\cdot$ day $^{-1} ;{ }^{+}$: 15001-30000 vehicles $\cdot$ day $^{-1} ;{ }^{\S}:>30000$ vehicles $\cdot$ day $^{-1}$, in street segment $<50 \mathrm{~m}$ away from home.

Substantial participation bias is unlikely since the prevalence of outcomes (except for a slightly higher prevalence of hay fever) and the proportion of car-traffic counts were not statistically different in children participating in skin-prick testing compared with those not participating (table 3 ). When additional socioeconomic information about individual city areas provided by the administration (percentage unemployed, percentage unemployed youth, percentage immigrants, average family size) were used for cluster analysis, no local effects on outcomes were seen (data not shown).

\section{Traffic counts}

Traffic counts in street segments varied from 2,600148,000 vehicles $\cdot$ day $^{-1}$. Figure 1 shows the places of residence in relation to street segments. SES and ETS exposure were

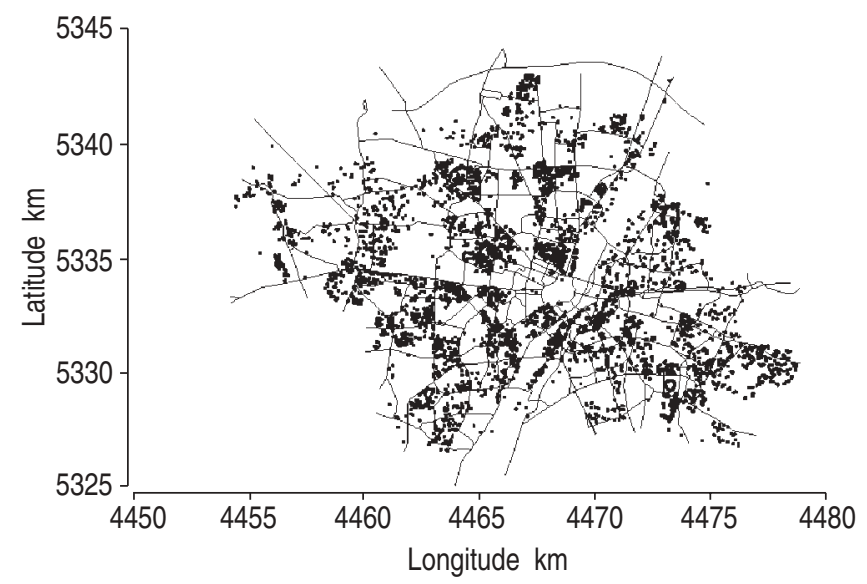

Fig. 1.-Places of residence of children and street segments in Munich. 
Table 4.-Respiratory and atopic outcomes in relation to traffic counts in the area of residence

\begin{tabular}{|c|c|c|c|c|}
\hline Outcome & $\begin{array}{l}\text { Crude reference } \\
\text { prevalence } \% \\
\text { (raw numbers) }\end{array}$ & Exposure tertile & $\begin{array}{l}\text { Crude prevalence } \% \\
\text { (raw numbers) }\end{array}$ & $\begin{array}{l}\text { Adjusted OR } \\
\quad(95 \% \mathrm{CI})\end{array}$ \\
\hline \multirow[t]{3}{*}{ Asthma } & \multirow[t]{3}{*}{$10.4(318 / 3071)$} & Low & $9.4(18 / 192)$ & $0.902(0.545-1.493)$ \\
\hline & & Medium & $9.6(20 / 208)$ & $0.931(0.576-1.506)$ \\
\hline & & High & $12.2(24 / 197)$ & $1.194(0.762-1.871)$ \\
\hline \multirow[t]{3}{*}{ Current asthma ${ }^{\#}$} & \multirow[t]{3}{*}{$5.0(157 / 3124)$} & Low & $3.1(6 / 196)$ & $0.607(0.264-1.396)$ \\
\hline & & Medium & $5.7(12 / 211)$ & $1.177(0.639-2.171)$ \\
\hline & & High & $8.6(17 / 197)$ & $1.790(1.051-3.048)^{\S}$ \\
\hline \multirow[t]{3}{*}{ Current wheeze ${ }^{\#}$} & \multirow[t]{3}{*}{$8.6(266 / 3085)$} & Low & $7.3(14 / 192)$ & $0.848(0.483-1.488)$ \\
\hline & & Medium & $8.5(18 / 211)$ & $1.008(0.609-1.669)$ \\
\hline & & High & $13.5(26 / 193)$ & $1.663(1.073-2.578)^{\S}$ \\
\hline \multirow[t]{3}{*}{ Cough $^{\top}$} & \multirow[t]{3}{*}{$18.0(559 / 3097)$} & Low & $18.7(36 / 193)$ & $1.049(0.720-1.528)$ \\
\hline & & Medium & $22.3(47 / 211)$ & $1.323(0.942-1.858)$ \\
\hline & & High & $26.8(52 / 194)$ & $1.622(1.162-2.266)^{f}$ \\
\hline \multirow[t]{3}{*}{ Hay fever } & \multirow[t]{3}{*}{$11.7(360 / 3082)$} & Low & $10.9(21 / 192)$ & $0.940(0.585-1.510)$ \\
\hline & & Medium & $12.4(26 / 209)$ & $1.061(0.688-1.638)$ \\
\hline & & High & $13.3(26 / 196)$ & $1.171(0.756-1.814)$ \\
\hline \multirow{3}{*}{$\begin{array}{l}\text { Skin-prick test } \\
\quad \geqslant 3 \mathrm{~mm}\end{array}$} & \multirow[t]{3}{*}{$19.4(341 / 1762)$} & Low & $17.9(20 / 112)$ & $0.846(0.509-1.405)$ \\
\hline & & Medium & $18.2(22 / 121)$ & $0.971(0.595-1.584)$ \\
\hline & & High & $23.4(26 / 111)$ & $1.373(0.857-2.200)$ \\
\hline \multirow[t]{3}{*}{ Pollen } & \multirow[t]{3}{*}{$13.9(243 / 1754)$} & Low & $14.2(16 / 113)$ & $0.961(0.551-1.677)$ \\
\hline & & Medium & $14.2(17 / 120)$ & $1.067(0.619-1.840)$ \\
\hline & & High & $18.9(21 / 111)$ & $1.567(0.940-2.613)^{+}$ \\
\hline \multirow{3}{*}{$\begin{array}{l}\text { Specific IgE } \\
\text { aeroallergens } \\
\geqslant 0.7 \mathrm{kU} \cdot \mathrm{mL}^{-1}\end{array}$} & \multirow[t]{3}{*}{$36.3(476 / 1311)$} & Low & $28.8(23 / 80)$ & $0.682(0.411-1.130)$ \\
\hline & & Medium & $34.7(34 / 98)$ & $0.933(0.600-1.453)$ \\
\hline & & High & $39.5(32 / 81)$ & $1.213(0.755-1.947)$ \\
\hline
\end{tabular}

OR: odds ratio; CI: confidence interval; Ig: immunoglobulin; low: 2600-15000 vehicles $\cdot$ day $^{-1}$; medium: $15001-30000$ vehicles $\cdot$ day $^{-1}$; high: $>30000$ vehicles. day ${ }^{-1}$ in street segment $<50 \mathrm{~m}$ away from home. ${ }^{\#}$ : with respective symptoms during the last 12 months; " morning cough during the last 12 months. ORs adjusted for age, sex, socioeconomic status, and family history of asthma, hay fever, or eczema. Traffic categories analysed versus rest of population (reference). ${ }^{+}: \mathrm{p}=0.05-\leqslant 0.10 ;{ }^{\S}: \mathrm{p}=0.01-\leqslant 0.05 ;{ }^{f}: \mathrm{p} \leqslant 0.01$.

linked with traffic exposure. Children living close $(\leqslant 50 \mathrm{~m})$ to a busy street $\left(>30,000\right.$ cars $\left.\cdot \mathrm{day}^{-1}\right)$ were more often of lower SES $(59.3 \%)$ compared with the total sample $(48.8 \%)$ and those $(44.3 \%)$ with no traffic count $\leqslant 300 \mathrm{~m}(\mathrm{p}<0.0001$; Cochran Armitage trend test). When the effect of traffic counts on outcomes was stratified for SES, no effect modification was seen. The same relationship was found for ETS exposure: $51.9 \%$ of those living close to a busy street were exposed compared with $40.0 \%$ in the total sample and $35.1 \%$ in the low traffic areas $(\mathrm{p}<0.0001)$.

When traffic counts at $\leqslant 50 \mathrm{~m}$ distance were used as an exposure variable and the outcomes were contrasted against the rest of the population (table 4), a significant association was found between total traffic count and cough, current asthma and wheeze, and a dose/response effect was suggested. When stratifying the population into children exposed and not exposed to ETS, an effect modification for ETS was seen. Among children with ETS exposure (table 5), traffic volume was significantly associated with current asthma, a positive skin-prick test and positive skin-prick tests to pollen. A dose/ response effect was again observed in this stratum. No significant effects of traffic on lung function and bronchial hyperreactivity were observed. In children without ETS exposure, the effect of traffic was statistically significant only for cough (data not shown).

When children were stratified by skin-prick test positivity, the associations between traffic and outcomes remained significant only for atopic children. This was, however, probably due to the small proportion of children with asthma and asthma symptoms in the nonatopic group leading to very small sample sizes for the highly exposed nonatopic children.

When the distance limit for roads defining high traffic exposure was increased from $50 \mathrm{~m}$ up to $100 \mathrm{~m}$, the association of traffic counts with current asthma (in children with
ETS exposure with asthma, skin-prick test and sensitisation to pollen) remained significant. For a distance limit of $300 \mathrm{~m}$, the association became less clear but was still significant with cough.

In addition to car-traffic volume, truck-traffic counts $(\sim 10 \%$ of total counts) were also available. When the latter were used in the analysis, approximately the same associations as with total traffic counts were found with the outcome variables (data not shown).

If the children living in areas with no available traffic count at $\leqslant 300 \mathrm{~m}$ distance were analysed separately, a tendency for relatively high prevalences of atopic diseases were found, although Ns: $6.3 \%$ current asthma (versus $4.8 \%$ in the rest of the population), $11.9 \%$ current hay fever (versus $11.7 \%$ ) and $22.6 \%$ had a positive skin-prick test (versus 18.7\%).

\section{Pollutant concentrations}

Estimated exposure to traffic-related pollutants, as calculated from the above-described model for the home of the children, was used as exposure variables in a multivariate logistic regression model. Results for the highest tertiles of high exposure versus low exposure are shown in table 6, while the same is presented for children additionally exposed to ETS in table 7.

Cough was associated with soot, benzene and $\mathrm{NO}_{2}$, current asthma with soot and benzene, and current wheeze with benzene and $\mathrm{NO}_{2}$, each without a clear dose/response gradient. No effect modification was found for exposure to ETS. No significant associations with lung function and bronchial hyperresponsiveness were detectable for any pollutant (data not shown). 
Table 5.-Respiratory and atopic outcomes in relation to traffic counts in the area of residence for children additionally exposed to environmental tobacco smoke

\begin{tabular}{|c|c|c|c|c|}
\hline Outcome & $\begin{array}{c}\text { Crude reference prevalence } \\
\% \text { (raw numbers) }\end{array}$ & $\begin{array}{l}\text { Exposure } \\
\text { tertile }\end{array}$ & $\begin{array}{l}\text { Crude prevalence \% } \\
\text { (raw numbers) }\end{array}$ & $\begin{array}{l}\text { Adjusted OR } \\
\quad(95 \% \mathrm{CI})\end{array}$ \\
\hline \multirow[t]{3}{*}{ Asthma } & \multirow[t]{3}{*}{$10.8(126 / 1169)$} & Low & $4.8(4 / 83)$ & $0.438(0.157-1.222)$ \\
\hline & & Medium & $11.0(11 / 100)$ & $1.009(0.521-1.957)$ \\
\hline & & High & $13.6(14 / 103)$ & $1.343(0.736-2.452)$ \\
\hline \multirow[t]{3}{*}{ Current asthma ${ }^{\#}$} & \multirow[t]{3}{*}{$5.2(62 / 1193)$} & Low & $1.2(1 / 83)$ & $0.232(0.032-1.700)$ \\
\hline & & Medium & $5.9(6 / 101)$ & $1.130(0.472-2.706)$ \\
\hline & & High & $9.7(10 / 103)$ & $2.047(1.005-4.171)^{\S}$ \\
\hline \multirow[t]{3}{*}{ Current wheeze } & \multirow[t]{3}{*}{$9.1(107 / 1178)$} & Low & $4.8(4 / 83)$ & $0.523(0.187-1.461)$ \\
\hline & & Medium & $9.9(10 / 101)$ & $1.095(0.550-2.179)$ \\
\hline & & High & $14.0(14 / 100)$ & $1.697(0.927-3.106)^{+}$ \\
\hline \multirow[t]{3}{*}{ Cough $^{\top}$} & \multirow[t]{3}{*}{$19.1(226 / 1186)$} & Low & $20.7(17 / 82)$ & $1.177(0.674-2.054)$ \\
\hline & & Medium & $25.7(26 / 101)$ & $1.487(0.927-2.385)^{+}$ \\
\hline & & High & $26.7(27 / 101)$ & $1.543(0.967-2.462)^{+}$ \\
\hline \multirow[t]{3}{*}{ Hay fever } & \multirow[t]{3}{*}{$10.4(123 / 1179)$} & Low & $6.1(5 / 82)$ & $0.578(0.227-1.472)$ \\
\hline & & Medium & $16.8(17 / 101)$ & $1.678(0.944-2.981)^{+}$ \\
\hline & & High & $15.7(16 / 102)$ & $1.739(0.967-3.126)^{+}$ \\
\hline \multirow[t]{3}{*}{ Skin-prick test $\geqslant 3 \mathrm{~mm}$} & \multirow[t]{3}{*}{$15.8(110 / 695)$} & Low & $13.7(7 / 51)$ & $0.785(0.339-1.817)$ \\
\hline & & Medium & $23.8(15 / 63)$ & $1.539(0.812-2.918)$ \\
\hline & & High & $28.8(15 / 52)$ & $2.670(1.353-5.268)^{f}$ \\
\hline \multirow[t]{3}{*}{ Pollen } & \multirow[t]{3}{*}{$11.8(82 / 694)$} & Low & $11.5(6 / 52)$ & $0.915(0.372-2.247)$ \\
\hline & & Medium & $19.4(12 / 62)$ & $1.662(0.829-3.331)$ \\
\hline & & High & $25.0(13 / 52)$ & $3.255(1.581-6.699)^{f}$ \\
\hline \multirow{3}{*}{$\begin{array}{l}\text { Specific IgE aeroallergens } \\
\geqslant 0.7 \mathrm{kU} \cdot \mathrm{mL}^{-1}\end{array}$} & \multirow[t]{3}{*}{$33.1(164 / 496)$} & Low & $25.7(9 / 35)$ & $0.655(0.296-1.451)$ \\
\hline & & Medium & $33.3(16 / 48)$ & $1.003(0.524-1.920)$ \\
\hline & & High & $45.0(18 / 40)$ & $1.761(0.897-3.458)^{+}$ \\
\hline
\end{tabular}

OR: odds ratio; CI: confidence interval; Ig: immunoglobulin; Low: 2600-15000 vehicles $\cdot$ day $^{-1}$; Medium: $15001-30000$ vehicles $\cdot$ day $^{-1}$; High: $>30000$ vehicles $\cdot$ day $^{-1}$ in street segment $<50 \mathrm{~m}$ away from home. ${ }^{\#}$ : with respective symptoms during the last 12 months. ": morning cough during the last 12 months. ORs adjusted for age, sex, socioeconomic status, and family history of asthma, hay fever, or eczema. Traffic categories analysed versus rest of population (reference). ${ }^{+}: \mathrm{p}=0.05-\leqslant 0.10 ;{ }^{\S}: \mathrm{p}=0.01-\leqslant 0.05 ;{ }^{f}: \mathrm{p} \leqslant 0.01$.

Table 6. - Respiratory and atopic outcomes in relation to estimated pollutant levels at residence

\begin{tabular}{|c|c|c|c|}
\hline Outcome & $\begin{array}{c}\text { Crude reference prevalence } \\
\% \text { (raw numbers) }\end{array}$ & $\begin{array}{l}\text { Crude prevalence } \% \\
\text { (raw numbers) }\end{array}$ & $\begin{array}{l}\text { Adjusted OR } \\
\quad(95 \% \mathrm{CI})\end{array}$ \\
\hline \multicolumn{4}{|l|}{ Soot } \\
\hline Asthma & $10.1(301 / 2982)$ & $13.2(26 / 197)$ & $1.423(0.920-2.201)$ \\
\hline Current asthma & $5.0(152 / 3031)$ & $8.0(16 / 201)$ & $1.763(1.021-3.044)^{\bullet}$ \\
\hline Current wheeze & $8.6(259 / 2996)$ & $11.2(22 / 197)$ & $1.409(0.883-2.248)$ \\
\hline Cough & $17.9(537 / 3008)$ & $24.1(48 / 199)$ & $1.483(1.055-2.086)^{\curvearrowleft}$ \\
\hline Hay fever & $11.9(357 / 2993)$ & $12.8(25 / 196)$ & $1.103(0.708-1.721)$ \\
\hline Skin-prick test & $20.5(344 / 1682)$ & $16.0(21 / 131)$ & $0.864(0.528-1.417)$ \\
\hline Pollen & $15.2(255 / 1675)$ & $12.3(16 / 130)$ & $0.904(0.520-1.573)$ \\
\hline Specific IgE aeroallergens & $36.8(463 / 1258)$ & $37.9(36 / 95)$ & $1.124(0.723-1.747)$ \\
\hline \multicolumn{4}{|l|}{ Benzene } \\
\hline Asthma & $10.1(302 / 2979)$ & $12.4(25 / 201)$ & $1.269(0.816-1.975)$ \\
\hline Current asthma & $5.1(153 / 3029)$ & $9.3(19 / 204)$ & $2.045(1.227-3.407)^{+}$ \\
\hline Current wheeze & $8.8(263 / 2992)$ & $13.0(26 / 200)$ & $1.646(1.062-2.552)^{\circ}$ \\
\hline Cough & $17.7(533 / 3005)$ & $23.4(47 / 201)$ & $1.423(1.010-2.005)^{\natural}$ \\
\hline Hay fever & $11.8(353 / 2988)$ & $10.9(22 / 201)$ & $0.900(0.565-1.434)$ \\
\hline Skin-prick test & $20.4(343 / 1684)$ & $14.6(18 / 123)$ & $0.768(0.453-1.300)$ \\
\hline Pollen & $15.0(251 / 1678)$ & $9.8(12 / 123)$ & $0.688(0.369-1.283)$ \\
\hline Specific IgE aeroallergens & $37.4(469 / 1255)$ & $34.8(31 / 89)$ & $0.983(0.619-1.563)$ \\
\hline \multicolumn{4}{|l|}{$\mathrm{NO}_{2}$} \\
\hline Asthma & $10.2(304 / 2980)$ & $12.1(24 / 199)$ & $1.282(0.817-2.010)$ \\
\hline Current asthma & $5.1(154 / 3029)$ & $7.4(15 / 202)$ & $1.655(0.944-2.901)^{\#}$ \\
\hline Current wheeze & $8.8(263 / 2992)$ & $12.1(24 / 198)$ & $1.579(1.005-2.482)^{\bullet}$ \\
\hline Cough & $17.9(538 / 3007)$ & $25.5(51 / 200)$ & $1.599(1.144-2.234)^{+}$ \\
\hline Hay fever & $11.8(352 / 2990)$ & $12.2(24 / 197)$ & $1.038(0.661-1.630)$ \\
\hline Skin-prick test & $20.5(344 / 1676)$ & $15.4(20 / 130)$ & $0.818(0.495-1.354)$ \\
\hline Pollen & $15.2(254 / 1669)$ & $10.9(14 / 129)$ & $0.777(0.433-1.394)$ \\
\hline Specific IgE aeroallergens & $37.1(464 / 1251)$ & $38.1(37 / 97)$ & $1.141(0.736-1.767)$ \\
\hline
\end{tabular}

OR: odds ratio; CI: confidence interval; Ig: immunoglobulin; $\mathrm{NO}_{2}$ : nitrogen dioxide. ORs adjusted for age, sex, socioeconomic status, and family history of asthma, hay fever, or eczema. High exposure tertiles analysed versus rest of population. Soot $\left(\mu \mathrm{g} \cdot \mathrm{m}^{-3}\right): 8.07-9.24,>9.24-10.73,>10.73$; Benzene $\left(\mu \mathrm{g} \cdot \mathrm{m}^{-3}\right): 4.74-5.31,>5.31-7.27,>7.27 ; \mathrm{NO}_{2}\left(\mu \mathrm{g} \cdot \mathrm{m}^{-3}\right): 42.87-47.15,>47.15-57.44,>57.44$. For brevity, ORs $(95 \% \mathrm{CI})$ and prevalences are only shown for highest traffic exposure tertile for each outcome variable. ${ }^{\sharp}: \mathrm{p}=0.05-\leqslant 0.10 ;{ }^{\uparrow}: \mathrm{p}=0.01-\leqslant 0.05 ;{ }^{+}: \mathrm{p} \leqslant 0.01$. 
Table 7.- Respiratory and atopic outcomes in relation to estimated pollutant levels at residence for children additionally exposed to environmental tobacco smoke

\begin{tabular}{|c|c|c|c|}
\hline Outcome & $\begin{array}{l}\text { Crude reference } \\
\text { prevalence \% } \\
\text { (raw number) }\end{array}$ & $\begin{array}{l}\text { Crude prevalence } \% \\
\text { (raw number) }\end{array}$ & $\begin{array}{l}\text { Adjusted OR } \\
\quad(95 \% \mathrm{CI})\end{array}$ \\
\hline \multicolumn{4}{|l|}{ Soot } \\
\hline Asthma & $10.3(117 / 1136)$ & $16.7(16 / 96)$ & $1.746(0.978-3.115)^{\#}$ \\
\hline Current asthma & $5.2(60 / 1156)$ & $10.1(10 / 99)$ & $2.070(1.013-4.231)^{\bullet}$ \\
\hline Current wheeze & $8.9(102 / 1144)$ & $13.5(13 / 96)$ & $1.582(0.848-2.950)$ \\
\hline Cough & $18.9(218 / 1151)$ & $27.6(27 / 98)$ & $1.668(1.042-2.670)^{\curvearrowleft}$ \\
\hline Hay fever & $10.5(120 / 1143)$ & $16.3(16 / 98)$ & $1.549(0.862-2.784)$ \\
\hline Skin-prick test & $17.3(113 / 655)$ & $19.7(13 / 66)$ & $1.223(0.629-2.379)$ \\
\hline Pollen & $13.3(87 / 654)$ & $16.7(11 / 66)$ & $1.363(0.669-2.777)$ \\
\hline Specific IgE aeroallergens & $33.4(156 / 467)$ & $34.0(16 / 47)$ & $0.980(0.512-1.874)$ \\
\hline \multicolumn{4}{|l|}{ Benzene } \\
\hline Asthma & $10.4(118 / 1130)$ & $14.6(15 / 103)$ & $1.437(0.797-2.588)$ \\
\hline Current asthma & $5.2(60 / 1150)$ & $11.4(12 / 105)$ & $2.407(1.235-4.692)^{+}$ \\
\hline Current wheeze & $9.3(106 / 1137)$ & $13.7(14 / 102)$ & $1.593(0.871-2.915)$ \\
\hline Cough & $18.6(213 / 1145)$ & $24.3(25 / 103)$ & $1.407(0.873-2.269)$ \\
\hline Hay fever & $10.5(119 / 1137)$ & $15.4(16 / 104)$ & $1.432(0.799-2.565)$ \\
\hline Skin-prick test & $16.9(110 / 651)$ & $19.4(13 / 67)$ & $1.274(0.655-2.479)$ \\
\hline Pollen & $12.9(84 / 651)$ & $13.4(9 / 67)$ & $1.109(0.517-2.377)$ \\
\hline Specific IgE aeroallergens & $34.3(158 / 461)$ & $30.6(15 / 49)$ & $0.860(0.448-1.653)$ \\
\hline \multicolumn{4}{|l|}{$\mathrm{NO}_{2}$} \\
\hline Asthma & $10.3(117 / 1131)$ & $15.5(15 / 97)$ & $1.563(0.865-2.826)$ \\
\hline Current asthma & $5.2(60 / 1151)$ & $9.1(9 / 99)$ & $1.837(0.873-3.867)$ \\
\hline Current wheeze & $9.0(103 / 1139)$ & $13.5(13 / 96)$ & $1.607(0.861-2.999)$ \\
\hline Cough & $18.9(217 / 1147)$ & $28.6(28 / 98)$ & $1.722(1.081-2.744)^{\natural}$ \\
\hline Hay fever & $10.3(117 / 1138)$ & $16.3(16 / 98)$ & $1.538(0.855-2.766)$ \\
\hline Skin-prick test & $17.3(112 / 649)$ & $21.7(15 / 69)$ & $1.442(0.765-2.718)$ \\
\hline Pollen & $13.3(86 / 648)$ & $17.4(12 / 69)$ & $1.487(0.747-2.963)$ \\
\hline Specific IgE aeroallergens & $34.0(157 / 462)$ & $35.8(19 / 53)$ & $1.093(0.595-2.007)$ \\
\hline
\end{tabular}

OR: odds ratio; CI: confidence interval; Ig: immunoglobulin; $\mathrm{NO}_{2}$ : nitrogen dioxide. ORs adjusted for age, sex, socioeconomic status, and family history of asthma, hay fever, or eczema. High exposure tertiles analysed versus rest of population. Soot $\left(\mu \mathrm{g} \cdot \mathrm{m}^{-3}\right): 8.07-9.24,>9.24-10.73,>10.73$; Benzene $\left(\mu \mathrm{g} \cdot \mathrm{m}^{-3}\right): 4.74-5.31,>5.31-7.27,>7.27 ; \mathrm{NO}_{2}\left(\mu \mathrm{g} \cdot \mathrm{m}^{-3}\right): 42.87-47.15,>47.15-57.44,>57.44$. For brevity, ORs $(95 \% \mathrm{CI})$ and prevalences are only shown for highest traffic exposure tertile for each outcome variable. ${ }^{\#}: \mathrm{p}=0.05-\leqslant 0.10 ;{ }^{\uparrow}: \mathrm{p}=0.01-\leqslant 0.05 ;{ }^{+}: \mathrm{p} \leqslant 0.01$.

\section{Discussion}

In this large population-based survey, high vehicle trafficdensity close to the home was related to respiratory complaints, such as cough, wheeze and current asthma in children. The authors also found an association between exposure to heavy road traffic and allergic sensitisation for a small subgroup, additionally exposed to ETS. High traffic-related air pollutant exposure was associated with asthma and cough, but not with allergic sensitisation.

Several methodological limitations must be considered before attempting to interpret these findings. The city of Munich provided traffic counts for all street segments with an a priori estimate of $>4,000$ vehicles $\cdot \mathrm{day}^{-1}$ only. In this city, most street segments are small side streets and had no counts available. This may have led to some misclassification of traffic exposure. Also, pollutant exposure values at the homes, derived from a validated model, were used to estimate personal exposure rather than direct personal samplers. This approach will only yield an approximation of real exposure.

Children living close to streets with heavy traffic had particular lifestyle characteristics, which make it difficult to differentiate a possible direct effect of car-traffic exposure from these influences. Their families were of a lower SES and their children were more often exposed to ETS. When the analyses were stratified for high/low SES, however, no effect modification for the traffic-related outcomes was seen. No clustering of outcomes was observed with local socioeconomic characteristics of the city areas. Still, a residual confounding effect of SES cannot be excluded, since Munich has no areas with obvious social deprivation. Children living in homes that were least exposed to traffic were at the other end of the socioeconomic spectrum. Atopic diseases have been found more often in affluent families [27, 28]. The beneficial effect of low traffic exposure might actually be obscured, as children from these families can be expected to have higher prevalences of these diseases due to lifestyle factors associated with high SES. Still, these observations must be interpreted with care as the assessment of SES rests on information on parental education and misclassification may have occurred. Interestingly, the study in children living close to a busy freeway in Holland showed an effect on asthma only in children with low-to-medium SES [15].

The advantages of this study are the large number of subjects, the population-based design and the GIS-based assessment of exposure using traffic counts or measurements of air pollutants rather than self-reports. The use of pollution exposure derived from a modelling approach, well validated across high-to-low exposure measurement sites, allows assessment of the plausibility of direct pollutant effects versus other traffic-related mechanisms.

Participation or reporting bias is a concern in studies where only subsamples of children take part in some of the measurements (such as skin-prick testing or serum sampling). Participation rates for allergy tests were indeed lower than for the questionnaire (table 1), but as outcomes and traffic exposure categories showed only minor differences between participating and nonparticipating children (table 3), it is 
unlikely that bias introduced by this effect can explain these results.

Two interesting observations can be derived from the data presented here. Firstly, high traffic exposure was associated with cough, asthma and wheeze in all children, and with atopic sensitisation in children additionally exposed to ETS. Similar associations with outcomes were seen for trafficrelated air pollution levels. The findings regarding asthma are in accordance with those reported for Dutch children living along busy freeways [10, 15]. A survey from Dresden found pollutant effects for bronchitis, nonatopic asthma and cough but not for atopic asthma, allergy and lung function [2]. However, exposure had changed over the lifetime of these children and may have differed during the early years crucial for allergy inception from the exposure measured later on.

A Swiss study reported traffic effects on pollen allergy for a subsample of the adults studied (those living $>10$ yrs at the same address) [16]. When effects are only found in subsamples in epidemiological studies, the question of multiple comparisons resulting in spurious findings must be considered. Biological plausibility may argue in favour of both the results in the Swiss study and the findings of the study reported here. Recently, ETS exposure was found to be associated with diminished lung function in children with low $\alpha_{1}$-antitrypsin levels [25] indicating that ETS exposure together with other detrimental factors may result in overt respiratory damage.

Secondly, when streets $>50 \mathrm{~m}$ from home were included in the exposure assessment, the traffic effect was diluted. A large study from Italy found effects only for reported lorry traffic at the street of residence, but not in the zone of residence [11]. The same weakening of effects was apparent in this study when mean yearly pollutant levels were used as the exposure variable. No significant effect on allergic sensitisation was seen for pollutant exposure. This could indicate that the observed effects of traffic in streets $<50 \mathrm{~m}$ from home on atopy are not caused by emissions from vehicles but rather due to residual confounding, e.g. socioeconomic characteristics associated with such a place of residence. Although the pollutant exposure assessment gave good results with $\sim 80 \%$ predictive power at the measurement stations, misclassification due to the limitations of the modelling approach cannot be excluded. This would equally result in a diminished association between estimated pollutants and outcomes.

A smaller study in 317 children from Düsseldorf, Germany, found exposure to $\mathrm{NO}_{2}$ as estimated from measured outdoor levels in front of the home (but not the personal sampler derived individual exposure) to be related to skin-prick tests positivity and specific $\operatorname{IgE}$ [29]. This could indicate that individual substances may not reflect the mechanism by which the traffic-associated health effects are caused. Alternatively, if traffic exposure at short distance were the cause for the increased prevalence of sensitisation, it would have to be mediated via an effect or substance that is less easily dispersed in the surroundings than benzene, soot or $\mathrm{NO}_{2}$. Larger particles may display such characteristics, and dust containing latex or carbon has been implicated in health effects of traffic [30]. However, a recent study found no increase in latex sensitisation in children living close to busy streets [31].

The less clear association of pollutants compared with traffic counts and lack of dose/response effect suggests that the observed association with traffic may not be mediated directly via the measured pollutants. Children living in areas with particularly low traffic exposure also had relatively high atopy prevalence, as well as a higher socioeconomic status. It is also possible that increased outcome prevalences are attributable to differences in lifestyle and/or living conditions related to poverty and low socioeconomic status rather than to traffic exposure itself.

\section{References}

1. Pekkanen J, Timonen KL, Ruuskanen J, Reponen A, Mirme A. Effects of ultrafine and fine particles in urban air on peak expiratory flow among children with asthmatic symptoms. Environ Res 1997; 74: 24-33.

2. Hirsch T, Weiland SK, von Mutius E, et al. Inner city air pollution and respiratory health and atopy in children. Eur Respir J 1999; 14: 669-677.

3. Takano H, Yoshikawa T, Ichinose T, Miyabara Y, Imaoka K, Sagai M. Diesel exhaust particles enhance antigeninduced airway inflammation and local cytokine expression in mice. Am J Respir Crit Care Med 1997; 156: 36-42.

4. Miyabara Y, Takano H, Ichinose T, Lim HB, Sagai M. Diesel exhaust enhances allergic airway inflammation and hyperresponsiveness in mice. Am J Respir Crit Care Med 1998; 157: 1138-1144.

5. Devalia JL, Bayram H, Rusznak C, et al. Mechanisms of pollution-induced airway disease: in vitro studies in the upper and lower airways. Allergy 1997; 52: Suppl. 38, 4551 .

6. Knox RB, Suphioglu C, Taylor P, et al. Major grass pollen allergen Lol $\mathrm{p} 1$ binds to diesel exhaust particles: implications for asthma and air pollution. Clin Exp Allergy 1997; 27: 246251.

7. Behrendt H, Becker WM, Fritzsche C, et al. Air pollution and allergy: experimental studies on modulation of allergen release from pollen by air pollutants. Int Arch Allergy Immunol 1997; 113: 69-74.

8. Emberlin J. Interaction between air pollutants and aeroallergens. Clin Exp Allergy 1995; 25: Suppl. 3, 33-39.

9. Oosterlee A, Drijver M, Lebret E, Brunekreef B. Chronic respiratory symptoms in children and adults living along streets with high traffic density. Occup Environ Med 1996; 53: 241-247.

10. Brunekreef B, Janssen NA, de-Hartog J, Harssema $\mathrm{H}$, Knape M, van Vliet P. Air pollution from truck traffic and lung function in children living near motorways. Epidemiology 1997; 8: 298-303.

11. Ciccone G, Forastiere F, Agabiti N, et al. Road traffic and adverse respiratory effects in children. SIDRIA Collaborative Group. Occup Environ Med 1998; 55: 771-778.

12. Wjst M, Reitmeir P, Dold S, et al. Road traffic and adverse effects on respiratory health in children. BMJ 1993; 307: 596-600.

13. Studnicka M, Hackl E, Pischinger J, et al. Trafficrelated $\mathrm{NO}_{2}$ and the prevalence of asthma and respiratory symptoms in seven year olds. Eur Respir J 1997; 10: 22752278 .

14. Weiland SK, Mundt KA, Ruckmann A, Keil U. Selfreported wheezing and allergic rhinitis in children and traffic density on street of residence. Ann Epidemiol 1994; 4: 243247.

15. van Vliet $\mathbf{P}$, Knape $\mathbf{M}$, de Hartog J, Janssen N, Harssema H, Brunekreef B. Motor vehicle exhaust and chronic respiratory symptoms in children living near freeways. Environ Res 1997; 74: $122-132$.

16. Wyler C, Braun-Fahrländer C, Künzli N, et al. Exposure to motor vehicle traffic and allergic sensitization. Epidemiology 2000; 11: 450-456.

17. Weiland SK, von Mutius E, Hirsch T, et al. Prevalence of respiratory and atopic disorders among children in the East and West of Germany five years after unification. Eur Respir $J$ 1999; 14: 862-870.

18. Asher MI, Anderson HR, Beasley R, et al. International Study of Asthma and Allergies in Childhood (ISAAC): rationale and methods. Eur Respir J 1995; 8: 483-491.

19. The International Study of Asthma and Allergies in Childhood Study Group. Worldwide variations in the prevalence of atopic diseases: the International Study of Asthma and Allergies in Childhood (ISAAC). Lancet 1998; 351: 12251232. 
20. Gardner RM, Hankinson JL, Clausen JL, Crapo RO, Johnson RL, Epler GR. Standardization of spirometry: 1987 update. Official statement of the American Thoracic Society. Am Rev Respir Dis 1987; 136: 1285-1298.

21. Riedler J, Reade T, Dalton M, Holst D, Robertson C. Hypertonic saline challenge in an epidemiologic survey of asthma in children. Am J Respir Crit Care Med 1994; 150: 1632-1639.

22. Zapletal A, Paul F, Samanek M. The role of modern techniques of lung function testing for the diagnosis of airway obstruction in children and adolescents. Z Erkrank Atm Org 1977; 149: 343-371.

23. Carr D, von Ehrenstein O, Wagner C, et al. Modelling air pollution on the basis of road traffic characteristics. Environ Res 2002; 90: 111-118.

24. Briggs DJ, Collins S, Elliott $\mathrm{P}$, et al. Mapping urban pollution using GIS: A regression based approach. Int $J$ Geogr Inform Sci 1997; 11: 699-718.

25. von Ehrenstein O, von Mutius E, Maier E, et al. Pulmonary function in school children with low levels of $\alpha_{1}$-antitrypsin and environmental tobacco smoke exposure. Eur Respir $J$ 2002; 19: 1099-1106.

26. Kabesch M, Schaal W, Nicolai T, von Mutius E. Lower prevalence of asthma and atopy in Turkish children living in Germany. Eur Respir J 1999; 13: 577-582.

27. Heinrich J, Popescu MA, Wjst M, Goldstein IF, Wichmann HE. Atopy in children and parental social class. Am J Public Health 1998; 88: 1319-1324.

28. Barbee RA, Lebowitz MD, Thompson HC, Burrows B. Immediate skin test reactivity in a general population sample. Ann Intern Med 1976; 84: 129-133.

29. Krämer U, Koch T, Ranft U, Ring J, Behrendt H. Trafficrelated air pollution is associated with atopy in children living in urban areas. Epidemiology 2000; 11: 64-70.

30. Williams B, Buhr M, Weber R, Volz M, Koepke J, Selner J. Latex allergen in respirable particulate air pollution. $J$ Allergy Clin Immunol 1995; 95: 88-95.

31. Hirsch T, Neumeister V, Weiland SK, et al. Traffic exposure and allergic sensitization against latex in children. J Allergy Clin Immunol 2000; 106: 573-578. 